\title{
Erratum: Lateral forces on circularly polarizable particles near a surface
}

Francisco J. Rodríguez-Fortuño, Nader Engheta, Alejandro Martínez \& Anatoly V. Zayats

Nature Communications 6:8799 doi: 10.1038/ncomms9799 (2015); Published 19 Nov 2015; Updated 14 Dec 2015

Due to errors in the production process data were missing in the original version of Fig. $4 \mathrm{~b}$. The correct version of this figure appears below.
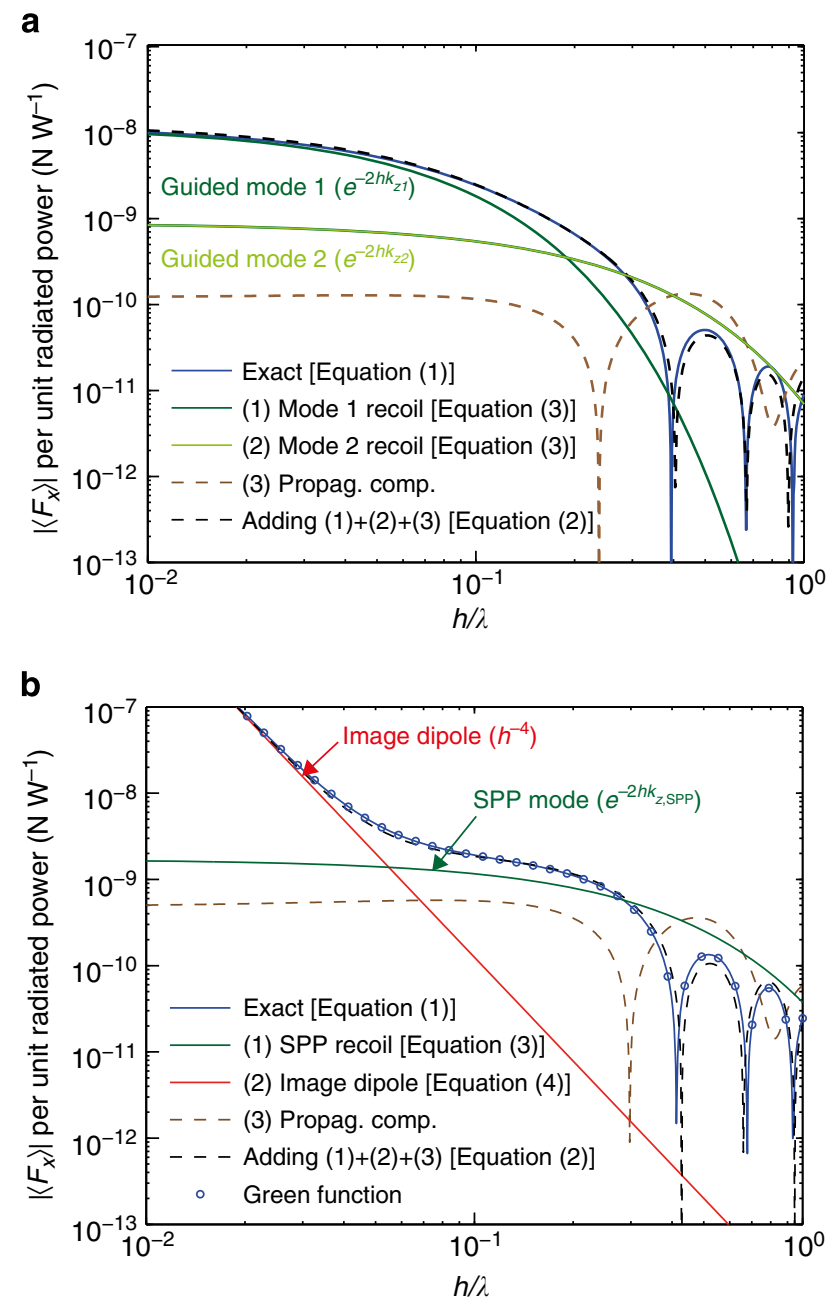

Figure 4

(c) (i) This work is licensed under a Creative Commons Attribution 4.0 International License. The images or other third party material in this article are included in the article's Creative Commons license, unless indicated otherwise in the credit line; if the material is not included under the Creative Commons license, users will need to obtain permission from the license holder to reproduce the material. To view a copy of this license, visit http://creativecommons.org/licenses/by/4.0/ 